\title{
Themes in Superhero-Based Television Shows: An Opportunity for the Development of Children and Adolescents Through Co-Viewing and Active Mediation
}

Raymond Y. Kim ${ }^{1}$, Morgan K. Moroi ${ }^{2}$, Amalia Brawley ${ }^{3}$, Marian Poley ${ }^{4}$, Tonya S. King ${ }^{5}$, Robert Olympia 6

1. Orthopedics, Penn State College of Medicine, Hershey, USA 2. Cardiac/Thoracic/Vascular Surgery, Penn State College of Medicine, Penn State Milton S. Hershey Medical Center, Hershey, USA 3. Obstetrics and Gynecology, Penn State College of Medicine, Penn State Milton S. Hershey Medical Center, Hershey, USA 4. Internal Medicine and Pediatrics, University of Maryland, Baltimore, USA 5. Public Health Sciences, Penn State College of Medicine, Hershey, USA 6. Emergency Medicine and Pediatrics, Penn State Hershey Medical Center, Hershey, USA

Corresponding author: Raymond Y. Kim, rkim@pennstatehealth.psu.edu

\begin{abstract}
The depiction of superheroes and comic book characters in television shows has become incredibly popular. The objective of this study was to determine the positive and negative themes depicted in a select number of superhero-based television shows. A total of 49 episodes from 10 superhero-based television shows were analyzed by four independent reviewers. The average number of positive and negative themes was 18.8 and 36.9 mean events per hour, respectively, for all included episodes. The most common positive themes in our sample were associated with service, teamwork, and encouragement, and the most common negative themes were associated with violence, bullying, and alcohol use. Although exposure to positive themes depicted in superhero-based television shows may be beneficial to the development of children and adolescents, pediatric health care providers should counsel families in an attempt to limit their exposure to violence and other negative themes depicted in this genre of television shows.
\end{abstract}

Categories: Pediatrics, Psychology

Keywords: superhero, television, media, violence, co-viewing, active mediation

\section{Introduction}

With on-demand Internet video streaming services like Netflix and Hulu becoming vogue, superhero-based television shows have become more accessible to viewers of all ages. Superheroes are often viewed by children as altruistic role models who make a positive impact on society. Nonetheless, superhero-based television shows often depict negative themes, such as violence, conflict, and substance use, which may influence risk-taking behaviors and choices made by children and adolescents. Repeated exposure to violence in media, whether in television shows, films, video games, or music, may pose a significant risk to the emotional and social development of children and adolescents. Published studies have shown that media violence may attribute to aggressive behavior, desensitization to violence, and nightmares in children [1-2]. Such findings have led the American Academy of Pediatrics to issue a formal statement on media violence, encouraging pediatricians to advocate for a safer media environment and to counsel patients and their parents to limit exposure to violence [3].

Kim et al. This is an open access article distributed under the terms of the Creative Commons Attribution License CC-BY 4.0., which permits unrestricted use, distribution, and reproduction in any medium, provided the original author and source are credited.
In 1996, the broadcasting industry created a voluntary ratings system named TV Parental Guidelines (http://www.tvguidelines.org), intended to accompany all television programming. In response to public concerns regarding increasingly explicit sexual content, graphic violence, and strong profanity in television programs, the rating system was established to alert parents to the content and age-appropriateness of television programming. Rating categories include the following: TV-Y (appropriate for all ages, especially children aged two to six years), TV-Y7 (appropriate for children aged seven years and above), TV-G (suitable for all ages; containing little or no violence, no strong language, and little or no sexual dialogue or situations), TV-PG (parental guidance suggested; may contain one or more of the following: some suggestive dialogue, infrequent coarse language, sexual situations, or moderate violence), TV-14 (parents strongly cautioned; unsuitable for children under the age of 14 years, may contain one or more of the following: intensely suggestive dialogue, strong coarse language, intense sexual situations, or intense violence), and TV-MA (mature audience only, unsuitable for children under age 17 years; containing one or more of the following: crude indecent language, explicit sexual activity, graphic violence). Unfortunately, studies have demonstrated that TV Parental Guidelines may be ineffective in discriminating risk behaviors, such as violence, sexual behavior, alcohol use, and smoking, in television shows [4-5]. As a consequence, children and adolescents may unknowingly be exposed to excess violence and other risk-taking behaviors while watching television shows that their parents believe to be age-appropriate. 


\section{Cureus}

A recently published study examined the positive and negative themes depicted in superhero-based films [6]. Based on their sample of 30 superhero-based films, the authors determined that the most common positive themes were "assisting others/protecting the public," "positive relationships with family/friends," and "teamwork/collaboration." The most common negative themes were "acts of violence/fighting," "use of guns/knives/lethal weapons", and "bullying/intimidation/torture". There have been no published studies analyzing themes depicted in superhero-based television shows. The objective of this study was to determine the positive and negative themes depicted in a select number of superherobased television shows. The authors hope that by identifying positive and negative themes found in superhero-based television shows, pediatric healthcare providers and parents will use this research to develop co-viewing strategies to help in the education and development of children and adolescents who watch this genre.

\section{Materials And Methods}

We conducted a content analysis study examining the positive and negative themes depicted in 10 different superhero television shows. The 10 television shows included in the analysis were selected from a list published on a popular television and film website, www.imdb.com, searching for "TV series/ TV miniseries, superhero (sorted by popularity ascending)" released between 2012 and 2017. For television shows that aired over multiple seasons, we analyzed the first season of each show. We used a random number generator to select which episodes to analyze for every show and analyzed at least $25 \%$ of episodes contained in every show included in the study.

A data collection instrument, developed by the authors and composed of a predetermined list of positive and negative themes (Table 1), allowed each of the four viewers (RYK, MKM, AMB, MP) to record each event associated with a theme depicted in each selected episode. Events, either positive or negative, were defined as actions, discussions, or references stated directly in the television script or implied during a scene. Actions performed in the television episode and then later referenced were coded only at the initial encounter. Certain coding guidelines were determined prior to viewing the episodes to standardize the data collection process. For example, when coding an extended fight sequence, a contained battle was coded as a single event ("Act of violence/fighting") while each use of a weapon ("Use of guns/knives/lethal weapons") was coded individually per event. Further, when coding a sequence involving several superheroes that are working together to protect the public, the entire sequence was coded as one event ("Helping/assisting others and mankind/protecting the public") while each interaction between superheroes during the sequence was coded as an individual event (“Teamwork/collaboration/cooperation”).

\section{Positive Themes \\ Honesty \\ Forgiveness/not holding a grudge \\ Overcoming adversity/obstacles/hardships \\ Self-sacrifice \\ Learning from past mistakes \\ Justice/Karma - getting what one deserves \\ Justice - triumph of law enforcement \\ Taking responsibility for actions/apologizing}

Helping/assisting others and mankind/protecting the public

Importance of intelligence over force and power (clever, wit)

Following the rules / Doing the right thing

Teamwork/collaboration/cooperation

Mentorship

Encouraging/Compliments

Preparation and setting goals

Combatting racism/prejudice

Self-defense

Negative Themes 


\section{Cureus}

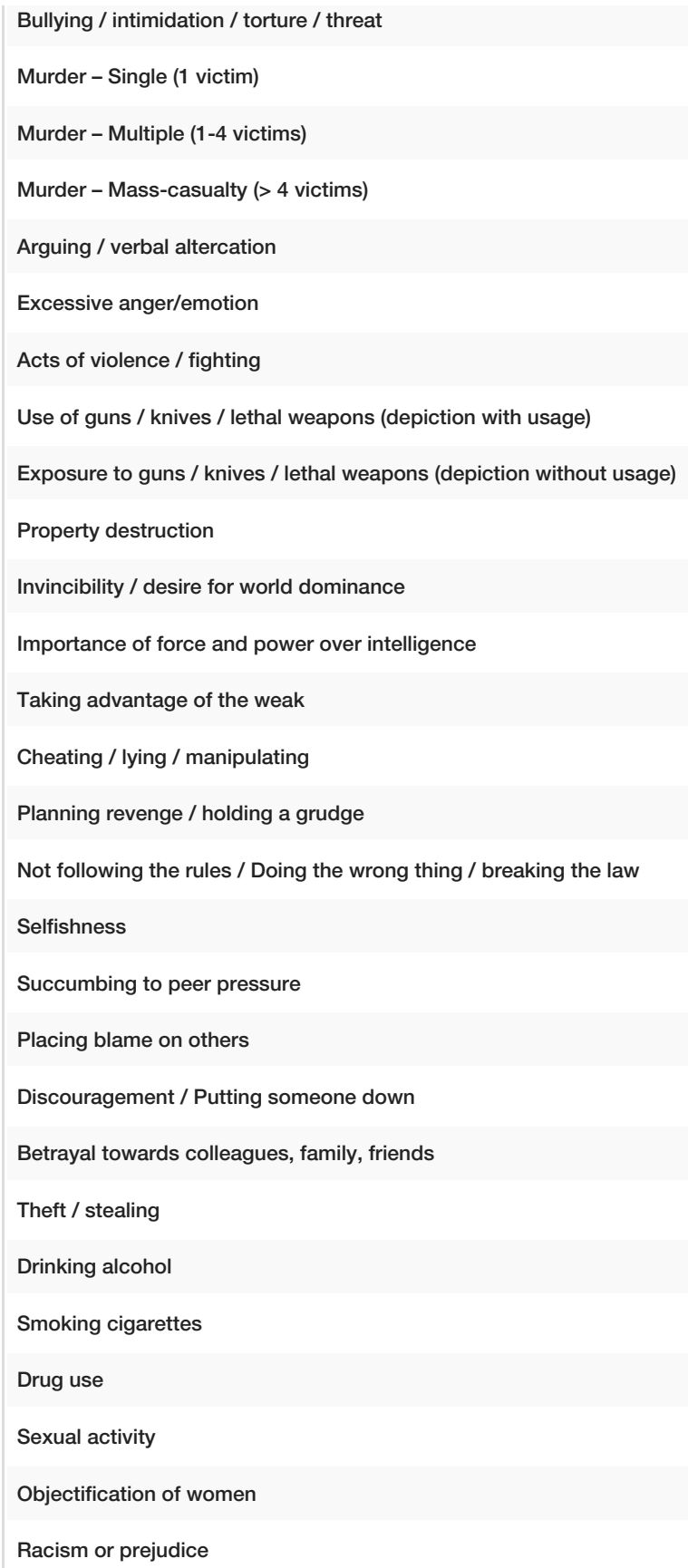

TABLE 1: List of positive and negative themes included in the data collection instrument

Each of the four reviewers watched and coded every episode included in the study independently. Data collection instrument sheets were collected by the primary investigator (RYK) and entered into Microsoft Excel (Microsoft Corporation, Redmond, Washington). The rates of total positive and negative themes per hour were then estimated using repeated measures Poisson regression models in SAS version 9.4 (SAS Institute, Cary, North Carolina) with adjustment for the reviewer, and reported with corresponding 95\% confidence intervals. The rates of individual positive and negative themes were estimated in the same manner.

The institutional review board at the Pennsylvania State Hershey Medical Center deemed the study exempt.

\section{Results}

A total of 49 episodes from our sample of 10 superhero-based television shows were analyzed. Table 2 describes the characteristics of the television shows that were included in the study. 


\section{Cureus}

\begin{tabular}{|c|c|c|c|c|c|c|}
\hline Title & $\begin{array}{l}\text { Year } \\
\text { released }\end{array}$ & Rating $^{* \star}$ & $\begin{array}{l}\text { Average length of episode } \\
\text { (minutes) }\end{array}$ & Network & $\begin{array}{l}\text { Dominant positive } \\
\text { theme } * \star \star\end{array}$ & Dominant negative theme ${ }^{\star * \star}$ \\
\hline $\begin{array}{l}\text { Agents of } \\
\text { S.H.I.E.L.D. }\end{array}$ & 2013 & PG & 45 & $A B C$ & Teamwork & $\begin{array}{l}\text { Exposure to guns/knives/lethal } \\
\text { weapons }\end{array}$ \\
\hline Arrow & 2012 & TV-14 & 42 & The CW & Helping Others & $\begin{array}{l}\text { Exposure to guns/knives/lethal } \\
\text { weapons }\end{array}$ \\
\hline Daredevil & 2015 & MA & 54 & $A B C$ & Helping Others & $\begin{array}{l}\text { Use of guns/knives/lethal } \\
\text { weapons }\end{array}$ \\
\hline Flash & 2014 & PG & 43 & The CW & Teamwork & Violence/Fighting \\
\hline Gotham & 2014 & TV-14 & 42 & FOX & Helping Others & Violence/Fighting \\
\hline Iron Fist & 2017 & MA & 55 & Netflix & Teamwork & Violence/Fighting \\
\hline Jessica Jones & 2015 & MA & 56 & Netflix & Helping Others & Violence/Fighting \\
\hline $\begin{array}{l}\text { Legends of } \\
\text { Tomorrow }\end{array}$ & 2016 & TV-14 & 42 & The CW & Teamwork & Violence/Fighting \\
\hline Luke Cage & 2016 & MA & 55 & Netflix & Helping Others & $\begin{array}{l}\text { Exposure to guns/knives/lethal } \\
\text { weapons }\end{array}$ \\
\hline Supergirl & 2015 & PG & 43 & The CW & Helping Others & Bullying/Torture \\
\hline
\end{tabular}

\section{TABLE 2: Superhero-based television show descriptions}

* General television show information from imdb.com

**PG (parental guidance suggested), TV-14 (parents strongly cautioned), MA (mature audience only)

${ }^{\star \star \star}$ Dominant themes were those with the highest number of events per hour

The average number of positive and negatives themes was 18.8 (95\% CI: 16.9 - 20.9) and 36.9 (95\% CI: 33.9 40.2) mean events per hour for all included shows, respectively (with adjustment for reviewer variability $\mathrm{p}<0.001$ ). Table 3 and Table 4 show the most common positive and negative themes depicted in our sample of superhero-based television shows, respectively. 


\section{Cureus}

\section{Positive themes}

Helping/assisting others and mankind/protecting the public

Teamwork/collaboration/cooperation

Encouraging/Compliments

Taking responsibility for actions/apologizing

Honesty

Importance of intelligence over force and power (clever, wit)

Preparation and setting goals

Justice/Karma - getting what one deserves

Forgiveness/not holding a grudge
All included episodes

3.59 [3.17 - 4.08]

3.51 [3.04-4.06]

2.38 [1.94 - 2.92]

$1.57[1.23-1.96]$

1.41 [1.12 - 1.78]

$0.85[0.63-1.14]$

$0.64[0.47-0.86]$

$0.56[0.37-0.85]$

$0.52[0.36-0.74]$

TABLE 3: Most common positive themes (reported as mean events per hour [95\% confidence interval]) depicted in our sample of superhero-based television episodes*

*Themes with mean events per hour under 0.5 for all included television episodes include: triumph of law enforcement $(0.43$ [0.26 - 0.72$])$, selfsacrifice $(0.42[0.28-0.60])$, overcoming adversity/obstacles/hardships $(0.36$ [ $0.23-0.56])$, mentorship $(0.31$ [ $0.17-0.56])$, and learning from past mistakes $(0.20[0.12-0.32])$.

Themes with mean events per hour too small to estimate for all included television episodes include: following the rules / doing the right thing, combatting racism/prejudice, and self-defense. 


\section{Cureus}

Negative themes

Acts of violence / fighting

Exposure to guns / knives / lethal weapons

Use of guns / knives / lethal weapons

Bullying / intimidation / torture / threat

Arguing / verbal altercation

Murder - Single (1 victim)

Property destruction

Drinking alcohol

Excessive anger/emotion

Cheating / lying / manipulating

Discouragement / Putting someone down

Planning revenge / holding a grudge

Betrayal towards colleagues, family, friends

Murder - Multiple (1-4 victims)

Theft / stealing
All included episodes

$5.49[4.91-6.14]$

4.74 [4.09- 5.50]

$4.53[4.02-5.11]$

3.85 [3.32 - 4.47]

3.01 [2.55-3.56]

$1.75[1.39-2.20]$

1.54 [1.23 - 1.93]

1.36 [1.10 - 1.69]

$1.32[1.02-1.70]$

$1.26[1.02-1.57]$

$1.01[0.69-1.48]$

0.88 [0.65 - 1.17]

$0.81[0.63-1.05]$

$0.63[0.44-0.92]$

$0.53[0.34-0.80]$

TABLE 4: Most common negative themes (reported as mean events per hour [95\% confidence interval]) depicted in our sample of superhero-based television episodes*

*Themes with mean events per hour under 0.5 for all included television episodes include: not following the rules / doing the wrong thing / breaking the law $(0.48[0.34-0.68])$, taking advantage of the weak $(0.33[0.22-0.49])$, sexual activity $(0.33[0.20-0.53])$, succumbing to peer pressure $(0.29$ $[0.19-0.44])$, drug use $(0.27[0.12-0.61])$, invincibility / desire for world dominance $(0.23[0.12-0.42])$, objectification of women $(0.20$ [0.10 - 0.39$])$, placing blame on others $(0.19[0.12-0.31])$, importance of force and power over intelligence $(0.17[0.09-0.33]$, selfishness $(0.16$ [0.08- 0.32$])$, and smoking cigarettes $(0.03[0.01-0.09])$

Themes with mean events per hour too small to estimate for all included television episodes include: murder - mass-casualty ( 4 victims) and racism or prejudice.

Based on our sample of superhero-based television shows, Agents of S.H.I.E.L.D, Daredevil, and Iron Fist had the highest overall positive theme mean events per hour (Table 5) while Flash, Arrow, and Iron Fist had the highest overall negative theme mean events per hour (Table 6). 


\section{Cureus}

\begin{tabular}{|c|c|c|}
\hline Title & Rating * & Mean events per hour \\
\hline Agents of S.H.I.E.L.D. & PG & 27.70 \\
\hline Daredevil & MA & 25.87 \\
\hline Iron Fist & MA & 24.08 \\
\hline Arrow & TV-14 & 19.55 \\
\hline Gotham & TV-14 & 19.03 \\
\hline Jessica Jones & MA & 18.06 \\
\hline Legends of Tomorrow & TV-14 & 16.55 \\
\hline Flash & PG & 14.85 \\
\hline Luke Cage & MA & 12.47 \\
\hline Supergirl & PG & 12.06 \\
\hline
\end{tabular}

TABLE 5: Total number of positive themes (mean events per hour) per television show season

${ }^{\star} \mathrm{PG}$ (parental guidance suggested), TV-14 (parents strongly cautioned), MA (mature audience only)

\begin{tabular}{|c|c|c|}
\hline Title & Rating * & Mean events per hour \\
\hline Flash & PG & 54.55 \\
\hline Arrow & TV-14 & 43.98 \\
\hline Iron Fist & MA & 40.37 \\
\hline Jessica Jones & MA & 37.17 \\
\hline Agents of S.H.I.E.L.D. & PG & 36.83 \\
\hline Luke Cage & MA & 36.22 \\
\hline Daredevil & MA & 34.02 \\
\hline Legends of Tomorrow & TV-14 & 30.36 \\
\hline Supergirl & PG & 27.64 \\
\hline Gotham & TV-14 & 27.15 \\
\hline
\end{tabular}

TABLE 6: Total number of negative themes (mean events per hour) per television show season

*PG (parental guidance suggested), TV-14 (parents strongly cautioned), MA (mature audience only)

The repeated measures Poisson regression models for the total number of both positive and negative themes per hour found a statistically significant amount of inter-rater variability among the reviewers $(\mathrm{p}<0.001$ in each of the models).

\section{Discussion}

From the introduction of Superman, which marked the rise of the Golden Ages of Comic Books in 1938, to today, when Marvel's Avengers: Endgame shattered the all-time global box-office opening record, superheroes have always been a vital aspect of American culture [7-8]. In the beginning, the original Superman was far different from the Superman we are familiar with today. Superhuman powers including flight, X-ray-vision, and wind control, are later developments that have been added throughout the years. In the early years, Superman did not fight the supervillains with the extreme violence that we have grown accustomed to today but rather fought the real villains of the New Deal era while standing up for the common people. The early villains consisted of bosses who failed to provide safe working environments, 
stockbrokers selling fraudulent stocks, and congressmen conspiring with corrupt corporations. It is no coincidence that the birth of the comic book era paralleled the Great Depression era and the struggles Americans experienced during that time.

In stark contrast, Superman of today can be seen in the film Man of Steel violently ending his epic battle against his adversary, General Zod by gruesomely snapping his neck, which seemed reflective of the darker and more violent nature of superhero cinema in the modern era. Research presented at the 2018 American Academy of Pediatrics National Conference and Exhibition reported that, contrary to the popular belief, protagonists ("good guys") performed more acts of violence in their sample of superhero-based films compared with antagonists ("bad guys") [9]. An increase in violence is not only true for superhero-based films. The violence depicted in films has doubled since the 1950 s, and gun violence in PG-13 rated films has more than tripled since 1985 [10]. Further, in a review of 74 G-rated animated films, every film in their study contained at least one act of violence with the majority (55\%) of the violence being associated with good or neutral characters utilizing a wide range of weapons during their violent acts [11]. Lastly, in a recently published study analyzing positive and negative themes depicted in 45 top-grossing films released between 2005 and 2015, the most common negative themes were associated with violence [12].

Based on our sample of superhero-based television shows, there were approximately twice as many negative themes as positive themes depicted. The most common positive themes were associated with service, teamwork, and encouragement. The most common negative themes were associated with violence, bullying, and alcohol use. These themes are similar to those depicted in a published study analyzing themes depicted in superhero-based films. There was a $60 \%$ overlap of the 10 most common positive themes and a $70 \%$ overlap of the 10 most common negative themes when comparing superhero-based films and television shows [6]. Common positive themes found in our sample of superhero-based television shows, and not in their sample of superhero-based films, included "honesty," "justice/karma - getting what one deserves," and "forgiveness/not holding a grudge." Common negative themes found in our sample of superhero-based television shows, and not in their sample of superhero-based films, included "property destruction," "drinking alcohol” and "discouragement/putting someone down.”

Given the significant amount of time children dedicate to media consumption, evidence has shown that visual media, such as television and film, contribute to a child's psychosocial development, both positively and negatively. The most common positive themes in our sample of superhero-based television shows were associated with service, teamwork, and encouragement. Children who are frequently exposed to positive themes in television shows may learn important life lessons from characters' situations and then translate these lessons into their own lives. Studies have shown that the content of visual media may help children develop positive thoughts and behaviors, such as sharing, improved social interactions, racial attitudes, cooperation, and empathy, and influence the perspective of gender-based roles in our society [13-14].

The most common negative themes in our sample of superhero-based television shows were associated with violence, bullying, and alcohol use. Several published studies show that media violence exposure may lead to the development of non-ideal behaviors such as aggression, bullying, antisocial attitudes, and other forms of violence [3,15-16]. The rate of bullying and cyberbullying has significantly increased over the past 10 years [17]. Studies have demonstrated that exposure to antisocial media content may be related to an increase in bullying and cyberbullying performed by their pediatric viewing audience [18-19]. Lastly, although our sample of superhero-based television shows demonstrate adults engaging in socially appropriate behavior with alcohol, depicting the intake of alcohol may glorify such behavior in the eyes of children and adolescents. Alcohol exposure in films has shown to be a predictor for the earlier initiation of heavy episodic drinking and sexual debut [20].

The TV Parental Guidelines were developed in response to public concerns regarding increasingly explicit sexual content, graphic violence, and strong profanity in television programs. Unfortunately, many parents believe the television rating system to be challenging; $68 \%$ of the parents of 10 to 17 years old reported that they do not use the television rating system at all [21]. Further, parents find the rating system to be highly inaccurate, with objective parental evaluation showing $50 \%$ of television shows rated TV- 14 to be inappropriate for their adolescent children [5]. Based on our sample of superhero-based television shows, we found inaccuracies in the content of violence. Both Flash and Arrow, rated PG and TV-14, respectively, depicted the highest negative theme mean-events per hour, compared with other shows in our sample that were rated MA. We suggest that television shows be assigned a rating based on both the severity of violence (moderate, intense, or graphic) and the number of violent events depicted per episode.

To help families prevent the harmful effects of unhealthy media exposure, the American Academy of Pediatrics recommends asking two media-related questions at every well-child visit: "How much recreational screen time does your child or teenager consume daily?" and "Is there a TV set or an Internetconnected electronic device in their bedroom [22]?" When children and adolescents are identified as significant viewers of visual media, clinicians should further evaluate for aggressive behaviors, fears, or sleep disturbances and intervene if deemed necessary.

Despite the availability of parental control settings available on modern televisions and hand-held devices to 
restrict younger viewers from age-inappropriate content, it is unrealistic to believe that children and adolescents will not be exposed to superhero-related television shows due to the availability of these shows on video-sharing online websites or via streaming on television or mobile electronic devices. It is important for pediatric health care providers and parents to be aware of the content of superhero-related television shows and to understand the impact that positive and negative themes have on the children and adolescents who view them. A method to optimize the development of children and adolescents who view superherorelated television shows involves co-viewing these shows as a family and active mediation. Parents play an active role in discussing both positive and negative themes depicted in the visual media to help their children think critically about distinguishing between right and wrong. Previous research has shown that active mediation was related to decreased levels of aggression, sexual behavior, and substance use in children exposed to age-inappropriate content [23]. We recommend the use of a template for co-viewing proposed by Bauer et al. ("HEROES/VILLAINS"), based on the most common positive and negative themes depicted in a sample of superhero-based films, along with a template developed by the authors ("TVSHOW" (Table 7)), based on positive and negative themes we found to be prevalent in our sample of superherobased television shows.

$\mathbf{T}$

Truthfulness / honesty

Vindication / justice

V /getting what one deserves

S Swallowing alcohol

Harbor no grudge

against / forgiveness

Obstruct one's

o hopes / discourage/

putting someone

down

W Wrecking property
Identify a character in the television show that demonstrates truthfulness and/or honesty. Why is it important to be honest? When was the last time that you were honest with someone? How did it make you feel?

Give an example of justice being served in a good way. What are the proper ways that you can attain justice?

Give an example of a character in the television show who uses or abuses alcohol? Were there any consequences to the character's use of alcohol? Do you drink alcohol? Have you dealt with any consequences to drinking alcohol? Have you ever been pressured to drink alcohol? How did you respond to this pressure?

Identify a character in the television show that forgives another character. Have you demonstrated forgiveness recently? How did it make you feel?

Identify a character in the television show that discourages another character. Has someone recently put you down or discouraged you to follow your dreams? How did you respond to this discouragement?

Identify a character in the television show that has destroyed someone's property. Have you ever destroyed someone else's property? Why did you do this? How could you have rectified the situation?

\section{TABLE 7: Template for co-viewing superhero-based television shows}

We encourage families to use the template below ("TVSHOW," focusing on superhero-based television shows), with the "HEROES/VILLAINS" template (based on themes depicted in a sample of superhero-based films) 6, either during or after viewing the television episode, to provoke thoughtful conversation and reflection by having the child answer each of the questions based on common positive and negative themes found in superhero-based television shows.

There are several limitations to our study. Since the television shows included in our sample were selected based on subjective reports of the "most popular" superhero-based television shows released between 2012 and 2017 as reported by one popular online site (www.imdb.com), our choices may not represent the most popular or most-watched shows by children and adolescents or be generalizable to television shows outside our release date range. As certain shows included in our study require a paid-subscription to services such as Netflix, it may be possible that certain children and adolescents may be inadvertently excluded from watching these shows. Another limitation of our study was the limited sampling of the episodes. As we randomly selected a set number of episodes to analyze for each show, we extrapolated the content of positive and negative themes based on our randomized sample of episodes and, therefore, our data may not represent the entire season for each included superhero-based television show.

The coding of the television show episodes also represents a limitation. We found a substantial inter-viewer variability between the reviewers for both positive and negative themes. Although coding guidelines were decided prior to viewing the study episodes, each reviewer may have interpreted scenarios and dialogue associated with positive and negative themes differently, depending on variables such as background, gender, race, and age of the reviewer. Furthermore, all the reviewers were adults, who may interpret themed events differently than children and adolescents. The reviewers were also all in the medical profession who were familiar with the presence of violence in media, which may have contributed to our own personal bias while watching the films. Although our objective was to determine the positive and negative themes depicted in a sample of superhero-based television shows, the actual number of events may not be as important as the positive and negative themes that are represented frequently or under-represented and 
require more emphasis in future television shows.

Although our primary goal was to determine the thematic content of superhero-based television shows in our sample, we did not determine the positive and negative effects that exposure to these themes have on their pediatric audiences.

\section{Conclusions}

Based on our sample of shows, there were approximately twice as many negative themes as positive themes depicted. Although exposure to positive themes found in superhero-based television shows may be beneficial to the development of children, pediatric health care providers should counsel children and their families in the attempt to limit their exposure to violence and other negative themes depicted in this genre of television shows. We encourage co-viewing and active mediation, focusing on depicted positive and negative themes, as a method to guide children and adolescents through critical periods of their mental and behavioral development.

\section{Additional Information}

\section{Disclosures}

Human subjects: Consent was obtained by all participants in this study. Penn State University Institutional Review Board issued approval N/A. The Institutional Review Board at the Pennsylvania State Hershey Medical Center deemed the study exempt. Animal subjects: All authors have confirmed that this study did not involve animal subjects or tissue. Conflicts of interest: In compliance with the ICMJE uniform disclosure form, all authors declare the following: Payment/services info: All authors have declared that no financial support was received from any organization for the submitted work. Financial relationships: All authors have declared that they have no financial relationships at present or within the previous three years with any organizations that might have an interest in the submitted work. Other relationships: All authors have declared that there are no other relationships or activities that could appear to have influenced the submitted work.

\section{References}

1. Hogan MJ: Adolescents and media violence: six crucial issues for practitioners . Adolesc Med Clin. 2005, 16:249-268. 10.1016/j.admecli.2005.02.008

2. Anderson CA, Berkowitz L, Donnerstein E, et al.: The influence of media violence on youth . Psychol Sci Public Interest. 2003, 4:81-110. 10.1111/j.1529-1006.2003.pspi_1433.x

3. Council on Communications and Media: Media violence. Pediatrics. 2009, 124:1495-1503. 10.1542/peds.2009-2146

4. Gabrielli J, Traore A, Stoolmiller M, Bergamini E, Sargent JD: Industry television ratings for violence, sex, and substance use. Pediatrics. 2016, 138:e20160487. 10.1542/peds.2016-0487

5. Walsh DA, Gentile DA: A validity test of movie, television, and video-game ratings . Pediatrics. 2001, 107:1302-1308. 10.1542/peds.107.6.1302

6. Bauer M, Georgeson A, McNamara C, Wakefield BH, King TS, Olympia RP: Positive and negative themes found in superhero films. Clin Pediatr (Phila). 2017, 56:1293-1300. 10.1177/0009922816682744

7. Kelley M: The Golden Age of Comic Books: Representations of American Culture from the Great Depression to the Cold War. Marquette University, Wisconsin; 2009.

8. 'Avengers Endgame' decimates record books with $\$ 1.2$ billion global debut . (2019). Accessed: September 11, 2019: https://www.boxofficemojo.com/article/ed2086732804/.

9. Muller JN, Loloi J, Moroco A, Portolese A, Wakefield BH, King TS, Olympia R: Violence depicted in superhero-based film stratified by protagonist/antagonist and gender. Cureus. 2020, 12:e6843. 10.7759/cureus.6843

10. Bushman BJ, Jamieson PE, Weitz I, Romer D: Gun violence trends in movies. Pediatrics. 2013, 132:10141018. 10.1542/peds.2013-1600

11. Yokota F, Thompson KM: Violence in G-rated animated films. JAMA. 2000, 24:2716-2720. 10.1001/jama.283.20.2716

12. Heasley VL, Li CF, Fatica JP, Magdeburger JA, Trinkkeller JM, King TS, Olympia RP: Themes associated with top-grossing films released from 2005 to 2015. Clin Pediatr. 2018, 57:528-536. 10.1177/0009922817730347

13. Christakis DA, Garrison MM, Herrenkohl T, Haggerty K, Rivara FP, Zhou C, Liekweg K: Modifying media content for preschool children: a randomized controlled trial. Pediatrics. 2013, 131:431-438. 10.1542/peds.2012-1493

14. Witt SD: The influence of television on children's gender role socialization . Child Educ. 2000, 76:322-324. 10.1080/00094056.2000.10522124

15. Paik H, Comstock G: The effects of television violence on antisocial behavior: a meta-analysis . Commun Res. 1994, 21:516-546. 10.1177/009365094021004004

16. Wood W, Wong FY, Chachere JG: Effects of media violence on viewers' aggression in unconstrained social interaction. Psychol Bull. 1991, 109:371-383. 10.1037/0033-2909.109.3.371

17. National Center for Education Statistics. Student reports of bullying: results from the 2015 School Crime Supplement to the National Crime Victimization Survey. (2016). Accessed: September 11, 2019: https://nces.ed.gov/pubsearch/pubsinfo.asp.

18. Nansel TR, Overpeck MD, Haynie DL, Ruan WJ, Scheidt PC: Relationships between bullying and violence among US youth. Arch Pediatr Adolesc Med. 2003, 157:348-353. 10.1001/archpedi.157.4.348 


\section{Cureus}

19. den Hamer AH, Konijn EA: Adolescents' media exposure may increase their cyberbullying behavior: a longitudinal study. J Adolesc Health. 2015, 56:203-208. 10.1016/j.jadohealth.2014.09.016

20. O'Hara RE, Gibbons FX, Li Z, Gerrard M, Sargent JD: Specificity of early movie effects on adolescent sexual behavior and alcohol use. Soc Sci Med. 2013, 96:200-207. 10.1016/j.socscimed.2013.07.032

21. Parents, children, and the television ratings system: two Kaiser Family Foundation surveys . (1998). Accessed: September 11, 2019: https://www.kff.org/other/parents-children-and-the-television-ratingssystem/.

22. Council on Communications and Media: Children, adolescents, and the media. Pediatrics. 2013, 132:958961. 10.1542/peds.2013-2656

23. Collier KM, Coyne SM, Rasmussen EE, et al.: Does parental mediation of media influence child outcomes? A meta-analysis on media time, aggression, substance use, and sexual behavior. Dev Psychol. 2016, 52:798812. 10.1037/dev0000108 